\title{
Palyatif Bakım Eğitimlerinin Sürdürülebilirliği
}

\author{
Dr. Öğr. Üyesi Betül Akalın ${ }^{1 *}$ \\ Yüksek l.isans Öğrencisi Ayşenur Modanlığlu²
}

Gelis tarihi: 29.08.2019

Kabul tarihi: 25.09.2019

\section{Atıf bilgisi:}

IBAD Sosyal Bilimler Dergisi

Sayı: Özel Sayı $\quad$ Sayfa: $432-440$

Yıl: 2019

This article was checked by iThenticate. Similarity Index $22 \%$.

${ }^{1}$ Sağllk Bilimleri Üniversitesi, Türkiye, betul.akalin@sbu.edu.tr,

ORCID ID 0000-0003-0402-2461

${ }^{2}$ Sağlık Bilimleri Üniversitesi, Türkiye, aysenurm.bilimsaglik@gmail.com ORCID ID 0000-0003-3781-6065

\footnotetext{
* Sorumlu yazar
}

$\ddot{O Z Z}$

Çalışmada palyatif bakım ünitesinde yatmakta olan hasta refakatçilerine verilen palyatif bakım eğitimlerinin evde bakım sürecindeki devamlılık durumlarının tespiti amaçlanmıştır. 01.09/31.11.2018 tarihleri arasında ünitede yatan 258 hastanın taburculuk tarihini takiben üç ayın sonundaki veriler çalışmaya dahil edilmiştir. Veri toplama aracı olarak oluşturulan soru formundaki bilgilerin toplanmasında hastane kayıtları ve hasta/hasta yakınları ile yapılan telefon görüşmeleri kullanılmıştır. Ortalama yaşın $77.29 \pm 13.64$, palyatif bakım ünitesindeki yatış gün sayısının ise $21.37 \pm 25,86$ olarak belirlendiği çalışmada $116(\% 44,97)$ hastanın vefat ettiği, $70(\% 27,13)$ hastaya iletișim verilerindeki eksik/ hata nedeniyle ulaşılamadığ 1 $72(\% 27,90)$ hastanın ise evde bakım sürecine devam ettiği saptanmıştır. Bu hastaların $60(83,33)$ '1 palyatif bakım sürecinde eğitim aldıklarını $50(83,33)$ ' si bu eğitimi evde bakım sürecinde kullandıklarını ve Palyatif bakım eğitiminden $\% 90$ oranında memnun oldukları belirtmişlerdir. Palyatif Bakım sürecinde hastaya refakat eden kișinin yakınlık durumu hastane otamasyon sistemine kaydı yapılmış $244(\% 94,57)$ hasta verisinden elde edilebilmiş olup yatan $175(\% 71,72)$ hastaya akrabalık bağı olan, $69(\% 28,27)$ hastaya ise bakıcı olarak çalıșan kișilerin refakat ettiği bulgusuna ulaşılmıştır. Evde bakım süreci geçiren tüm (ex ve yaşayan) hastalara ilişkin refakatçi bilgisi, konuşmak istememe, bilgisizlik, kurum ve çalısanlara tepki, yas süreci gibi nedenlerle $93(\% 88,57)$, hastanede refakatçilik yapan kişinin evde bakım sürecine devamlılığı bilgisi ise $95(90,47)$ hasta yakınından elde edilebilmiștir. Bu hastaların evde bakımı akrabalık bağı olan (eș, kızı, oğul, anne, gelin, enişte v.b) $48(\% 51,61)$, bakıcı olarak $45(\% 48,38)$ kişı tarafindan sağlandığı bulgusuna ulaşılmıştır. Hastanede hasta refakatçisi olarak bulunup evde bakım sürecinde de devam eden kişilerin 78 (\%82,11)'nin aynı kişi, $17(\% 17,89)^{\prime}$ sinin ise farklı kişiler olduğu tespit edilmiştir. Sonuç olarak taburculuklarından üç ay sonra hastaların $\% 44,97$ oranında vefat ettiği, yatış sürecinde palyatif bakım eğitimi alan bireylerin, evde bakım sürecinde de $\% 82,11$ oranında aynı kiși olarak bakım devamlılığı sağladığı, \%83,33 oranında aldıkları eğitimi evde kullandıklarını ve $\% 90$ oranında aldıkları eğitimden memnun kaldıkları ve bu sebeple etkili eğitimin karşılığının bulunduğu sonucuna ulaşıldı.

Anahtar Kelimeler: Palyatif Bakım, hasta/refakatçi eğitimi, memnuniyet, yaşam kalitesi, hasta kayit 


\title{
Sustainability of Palliative Care Trainings Assist
}

\author{
Assist. Prof. Dr. Betül Akalın ${ }^{1^{*}}$ \\ Master Stu. Ayşegül Modanlıŏglu
}

First received: 29.08 .2019

Accepted: 25.09.2019

\section{Citation:}

IBAD Journal of Social Sciences

Issue: Special Issue Pages: 432-440

Year: 2019

This article was checked by iThenticate. Similarity Index $22 \%$.

1 University of Health Sciences, Turkey, betul.akalin@sbu.edu.tr, ORCID ID 0000-0003-0402-2461

2 University of Health Sciences, Turkey, aysenurm.bilimsaglik@gmail.com,

ORCID ID 0000-0003-3781-6065

* Corresponding Author

\begin{abstract}
In this study, it is aimed to determine the continuity of the palliative care trainings given to the accompanying patients in the palliative care unit during the home care process. Data from 258 patients hospitalized in the unit between 01.09 / 31.11.2018 at the end of three months following the discharge date were included in the study. Hospital records and telephone interviews with patient / patient relatives were used to collect the information in the questionnaire which was formed as a data collection tool. The mean age was $77.29 \pm 13.64$ years and the number of hospitalization days in the palliative care unit was $21.37 \pm 25.86$ years. It was found that $116(44.97 \%)$ patients died, $70(27,13 \%)$ patients could not be reached due to incomplete / error communication data, and $72(27,90 \%)$ patients continued home care process. 60 $(83,33)$ of these patients received training in the palliative care process, $50(83,33)$ stated that they used this training in the home care process, and they were $90 \%$ satisfied with the palliative care training. In the palliative care process, degree of affinity of the person accompanying the patient could be obtained from 244 $(94.57 \%)$ patient data which was registered to the hospital automation system. In the study, it was found that $175(71.72 \%)$ inpatients were accompanied by relatives and $69(28.27 \%)$ were accompanied by caregivers. $93(88.57 \%)$ of all patients (ex and living) undergoing the home care process due to reasons such as companionship, unwillingness to talk, ignorance, reaction to institutions and employees, mourning process, and the attendance of the person performing hospital care to home care process 95 (90) (47). It was found that these patients were provided with home care by $48(51.61 \%)$ people who had kinship bond (spouse, daughter, son, mother, bride, brother-in-law, etc.) and $45(48.38 \%)$ people as careers. It was found that 78 $(82.11 \%)$ of the people who were in the hospital as a companion and continued in the same way in the home care process were the same person and $17(17.89 \%)$ were different people. As a result, $44.97 \%$ of the patients died three months after their discharge, the individuals who received palliative care training during the hospitalization period, maintained the same care as $82.11 \%$ in the home care process, $83.33 \%$ used the education they received at home and It was concluded that they were satisfied with the training they received at a rate of $90 \%$ and therefore effective training was rewarded.
\end{abstract}

Keywords: Palliative care, patient/ relative education, satisfaction, quality of life, patient record 


\section{GíRiș}

Yaşlı ve hasta bakımı büyük bir özen ve devamlılık gerektiren bir süreçtir. Bu sürecin doğru yönetilmesi oluşacak olan olumsuzlukları en aza indirir. Hasta ve bakım verenlerde hastalık seyri boyunca gerekli olan tutum, davranış ve bilinç düzeyini artırmayı amaçlayan hasta eğitimi; "inanç, değer ve motivasyondan etkilenen sağlık davranışlarına ilişkin bilginin verilmesi veya sağlıkla ilgili bilgiyi elde etme, özümseme ve davranışa dönüştürme olarak tanımlanır" (Avşar, 2009; Bruccoliere, 2000; Whitehead, 2004). Sağlık eğitiminde başarı, planlanan eğitimin davranışa dönüşmesi devamında ise sağlık üzerinde pozitif etkisinin görülmesi ile ifade edilir (Avşar ve Kaşıkcı, 2009; Özden, 2003; Şenyuva ve Taşocak, 2007). Başarılı hasta bakım eğitimlerinin, stres düzeyinin azaltılmasında, memnuniyet düzeyinin yükseltilmesinde (Hoving et al., 2010), hastanın öz bakım becerilerinin güçlendirilmesi ve kaliteli yaşam düzeyinin artırılmasında (Aziznezhad et al 2010), maliyetin düşürülmesinde, hastalık ve ölüm oranlarının azaltılması ve hastanede yatış süresinin kısaltılmasında (Hoving et al., 2010) olumlu yönde etkisinin olduğu belirtilmektedir (Yıldırım, Çiftçi ve Kaşıkçı, 2017).

Geleneksel yöntemde ülkemizde mevcut aile yapısı evde bakım gerektiren hastalara yönelik ihtiyacı önemli düzeyde karşılarken günümüzde artan nüfus, kentleşme, çekirdek aileye geçiş, ekonomik sıkıntılar, kadınların çalışma hayatına katılması, iletişim çatışmaları gibi sayılabilecek sebeplerle bu ihtiyacın karşılanması güçleşmiştir (Bahar ve Parlar, 2007). Yine son dönem hastalara yönelik bakım hizmetlerinin uzun dönem ihmal edilmesinde aile yapısı, palyatif bakım uzmanlığının bulunmaması, hasta ve çalışan düzeyinde yeterli farkındalığın oluşmaması sayılabilir (Kıvanç, 2017). Bu süreç hastanın toplumdan soyutlanmasına, maliyetlerin artmasına, gereksiz girişimlere, hasta ve bakım verenlerin üzerinde hastanede kalmanın getirdiği fiziksel, psikolojik ve sosyal sorunlara sebep olmaktadir (Bahar ve Parlar, 2007).

Oluşan ihtiyaç doğrultusunda ülkemizde 2010 yılı başı itibari ile 10 adet olan palyatif bakım merkezleri gereksiz girişimleri azaltması, maliyetleri düşürmesi, semptom yönetimi, zamanın verimli kullanılması gibi birçok sistem yönetim sürecini kolaylaştırıcı etkisinin bulunması sebebiyle çok hızlı bir artış göstermiştir (Aydoğan ve Uygun, 2011; Gültekin vd., 2010). Dünya Sağlık Örgütü (DSÖ)'nün tanımına göre palyatif bakım; "Yaşamı tehtit edici hastalıkların erken teşhis edilmesi, doğru değerlendirilmesi, bu hastalıklar yoluyla oluşan ağrı ve diğer fiziksel, psikososyal ve ruhsal problemlerin tedavi edilmesi yoluyla, söz konusu hastalığın önlenmesi ve rahatsızlıkların giderilmesini sağlayarak hastaların ve ailelerinin yaşam kalitesini artıran bir yaklaşım" olarak değerlendirmektedir (TDK; Connor ve Bermedo, 2014).

Palyatif bakımın hedefi hasta ve ailelerin yaşam kalitesini artırmaya yönelik çalışmaları kapsar. $\mathrm{Bu}$ amaçla primer hastalığın kontrolü dışında hasta ve yakınlarına duygusal destek, bilgilendirme, eğitim, iletişim, sosyal hizmet gibi çalışmaları kapsamlı bir çerçevede ele alır. Sağlık Bakanlığı Palyatif Bakım Hizmetlerinin Uygulama Usul ve Esasları Hakkında Yönerge 'de, eğitim maddesi, hasta ve yakınlarına içerisinde bulundukları durum ve beklentileri göz önünde bulundurularak eğitim ve bilgi verilmesi gerektiğini ifade etmektedir (Kıvanç, 2017; Kamu Hastaneleri Genel Müdürlüğü (KHGM, 2019). Bu amaç doğrultusunda palyatif bakımda verilen eğitim, hasta ve bakım veren refakatçiye bilgiyi elde etme, beceri kazandırma, var olan kabiliyetlerin devamlılığı ve geliştirilmesi, öz bakım becerileri, sosyal yaşama katılımın sağlanması gibi bilişsel, duyusal ve psikomotor ihtiyaçları gidermeye ve geliştirmeye yönelik çalışmalardır (Mollaoğlu, Özkan ve Kars, 2011). Sürecin sağlıklı işleyebilmesi nitelikli personel, etkili ve verimli eğitim programları ve sonuç değil süreç odaklı çalışmalar gerektirir.

$\mathrm{Bu}$ çalışmada palyatif bakım ünitesinde yatmakta olan hasta yakınlarına, hasta ve bakım vericinin yaşam kalitesini yükseltmeye yönelik eğitim verilip verilmediği, verilen palyatif bakım eğitimlerinin, hastaların taburculuklarından sonra da kullanılıp kullanılmadığının tespiti, eğitimden kazanılan faydaların memnuniyete etkisi, eğitimi alan kişilerin bakım sürecindeki devamlılık durumlarının tespiti amaçlanmıştır. 


\section{GEREÇ VE YÖNTEM}

\subsection{Araştırmanın türü:}

Çalışma kesitsel ve retrospektif niteliktedir.

\subsection{Araştırmanın evreni ve örneklem seçimi:}

Çalışmanın evrenini bir kamu hastanesinin palyatif bakım ünitesinde yatan hastalar, örneklem büyüklüğ̈̈ ise 01.09.2018/01.03.2019 tarihleri arasında ünitede yatan 258 hasta/refakatçileri oluşturmaktadır.

\subsection{Araştırmanın uygulama izni:}

Çalışmanın yapılabilmesi için hastane başhekimliğinden kurum izni ve çalışmanın yürütülebilmesi için de Sağlık Bilimleri Üniversitesi Hamidiye Girişimsel Olmayan Araştırmalar Etik Kurulundan (Tarih: 26.07.2019; Karar No: 19/77) etik kurul izni alınmıştır.

\subsection{Veri toplama aracı:}

Veri toplama aracı olarak oluşturulan soru formundaki bilgilerin toplanmasında, ilgili hastanenin istatistik biriminden alınan palyatif bakıma yatışı yapılan hastalara ilişkin retrospektif hastane kayıtları ve sistemden sağlanan iletişim numaraları üzerinden tek tek hasta/hasta yakınları ile yapılan telefon görüşmeleri kullanılmıştır.

Soru formu ile hastanın yaşı, telefon ve dosya numarası, palyatif bakıma yatış ve taburculuk tarihi, palyatif bakım sürecinde yanında kalan ve eğitim alan refakatçinin kim olduğu, yatış sırasında eğitim verilip verilmediği, bu bilgileri evde bakım sürecinde kullanıp kullanamadıkları, eğitimden memnuniyet, eğitimi alan refakatçinin evde bakım devamlılığının olup olmadığı ve eksitus bilgisi kayıt altına alınmıştır. Soru formu Tablo 1. de gösterilmiştir.

Tablo 1: Hasta Bilgileri Soru Formu

\begin{tabular}{|c|c|c|c|c|c|c|c|c|c|c|c|c|c|c|}
\hline \multicolumn{15}{|c|}{ Palyatif Bakım Ünitesinde Verilen "Hasta Bakım Eğitimlerinin” Evde Bakım Sürecindeki Sürdürülebilirliği } \\
\hline & & & & & & & & Eğiti & Alma & $\begin{array}{l}\text { Eğiti1 } \\
\text { Kulla }\end{array}$ & & Mem & niyet & \\
\hline $\begin{array}{l}\text { Tlf } \\
\text { No }\end{array}$ & $\begin{array}{l}\text { Dosya } \\
\text { No }\end{array}$ & Yaş & $\begin{array}{l}\text { Hasta } \\
\text { Adı } \\
\text { Soyadı }\end{array}$ & $\begin{array}{l}\text { Yatış } \\
\text { Tarih } \\
\mathrm{i}\end{array}$ & $\begin{array}{l}\text { Taburculu } \\
\text { k Tarihi }\end{array}$ & $\begin{array}{l}\text { Hastanede } \\
\text { Refakatçi }\end{array}$ & $\begin{array}{l}\text { Evde } \\
\text { Bakım } \\
\text { Refakatçi }\end{array}$ & Evet & $\begin{array}{l}\text { Hay1 } \\
\mathrm{r}\end{array}$ & Evet & $\begin{array}{l}\text { Hay1 } \\
\mathrm{r}\end{array}$ & Evet & $\begin{array}{l}\text { Hay1 } \\
\mathrm{r}\end{array}$ & Ex- Bilgisi \\
\hline & & & & & & & & & & & & & & \\
\hline & & & & & & & & & & & & & & \\
\hline
\end{tabular}

Palyatif bakımda yatmakta olan hastaların yaşam süresinin sınırlı olması, primer hastalığın kontrolünün yanında fiziksel, psikolojik, psikososyal ve ekonomik açıdan hızlı bir düzen gerektirmesi nedeniyle üç aylık bir sürecin yeterli olduğu düşünülmüş, bu nedenle 01 Eylül-31 Kasım 2018 tarihleri arasında palyatif bakım ünitesine yatış yapan hastaların taburculuk tarihinden itibaren 3 ayın sonundaki bilgileri çalışmaya esas alınmıştır.

İlk üç ayda, evde bakım sürecinde, exitus olduğu tespit edilen hastaların yakınlarına, palyatif bakımdan kazanılan edinimlerin değerlendirilmesi yönünde yeterli süreleri olmadığı düşünülerek eğitim alma, kullanma ve memnuniyet durumu ile ilgili temalar sorulmamış, palyatif bakımda yatmakta iken eksitus olan hastaların yakınları ile ise telefon görüşmesi yapılmamıştır.

\subsection{Verilerin Analizi:}

Araştırmanın analizi SPSS 25 programı ile tanımlayıcı istatistiksel veriler yüzde, frekans, ortalama değerleri hesaplanarak yapılmıştır.

\section{6. Çalışmanın Sınırılıkları:}

Çalışmada ölüm oranının yüksek olması, beraberinde yas sürecinin devam etmesi ve veri eksikliğinden dolayı bazı hastalara ulaşılamaması evde bakım sürecine ilişkin detaylı bilgi elde edilmesinde kişi sayısının azlığı çalışmanın sınırlılığını oluşturmaktadır. 


\section{BULGULAR}

Belirlenen çalışma aralığında palyatif bakımda yatışı yapılan 258 hasta tespit edilmiştir. $\mathrm{Bu}$ hastalarının yaş aralığı 25-105 arasında değişmekte olup ortalama yaş 77,29 $\pm 13,64$ olarak hesaplandı.

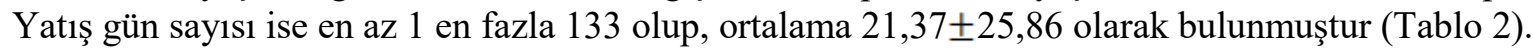

Tablo 2. Hastaların yaş ve palyatif bakım yatış süreleri

\begin{tabular}{llccc}
\hline & ort & ss & min & $\max$ \\
\hline Yaş & 77.29 & 13.64 & 25 & 105 \\
\hline Hastanede Yatış Süresi & 21.37 & 25.86 & 1 & 133
\end{tabular}

Çalışmada $35(\% 13,57)$ hasta ile hastane otomasyon sisteminde kaydedilen telefon bilgilerindeki eksiklikler nedeniyle iletişim kurulamamış, $35(\% 13,57)$ kişiye ise hatalı veri girişi nedeni ile ulaşılamamıştır (Tablo3).

Tablo 3. Hastalara ulaşıılma durumları

\begin{tabular}{l|l|l}
\hline Hastalara Ulaşım & $\mathbf{n}$ & \% \\
\hline Telefon bilgisi eksik & 35 & 13.57 \\
\hline Ulaşılamadi & 35 & 13.57 \\
\hline Ulaşılan hasta & 188 & 72.86 \\
\hline Toplam & 258 & 100 \\
\hline
\end{tabular}

Hastane kayıtlarından ve hasta yakınlarından ulaşılan 258 hastaya ilişkin edinilen veriler doğrultusunda $83(\% 32,17)$ hastanın palyatif bakım sürecinde, $33(\% 12,80)$ hastanın ise ilk 3 ayda, evde bakım sürecinde olmak üzere toplam 116 hastanın vefat ettiği, $72(\% 27,90)$ hastanın ise evde bakım sürecine devam ettiği bulgusuna ulaşılmıştır (Tablo4).

Tablo 4. Hastaların ex / hayatta olma durumları

\begin{tabular}{l|l|l}
\hline Yaşam Bilgisi & $\mathbf{n}$ & $\mathbf{\%}$ \\
\hline Palyatif bakım sırasında hastanede ex & 83 & 32.17 \\
\hline Taburculuk sonrası ilk 3 ay içinde ex & 33 & 12.80 \\
\hline Toplam eksitus & $\mathbf{1 1 6}$ & $\mathbf{4 4 , 9 7}$ \\
\hline Hayatta & 72 & 27.90 \\
\hline Bilinmiyor & 70 & 27.13 \\
\hline Genel Toplam & 258 & 100 \\
\hline
\end{tabular}

Palyatif Bakım sürecinde hastaya refakat eden kişinin yakınlık durumu hastane otomasyon istemine kaydı yapılmış $244(\% 94,57)$ hasta verisinden elde edilebilmiş, aynı zamanda ulaşılan hasta yakınlarından tekrar sorgulanmıştır. Yatan $175(\% 71,72)$ hastaya akrabalık bağı olan, $69(\% 28,27)$ hastaya ise bakıcı olarak çalışan kişilerin refakat ettiği bulgusuna ulaşılmıştır (Tablo 5).

Evde bakım süreci geçiren $105(\% 40,70)$ hastaya ilişkin refakatçi bilgisi, konuşmak istememe, bilgisizlik, kurum ve çalışanlara tepki, yas süreci gibi nedenlerle $93(\% 88,57)$, hastanede refakatçilik yapan kişinin evde bakım sürecine devamlılığ bilgisi ise $95(90,47)$ hasta yakınından elde edilebilmiştir. Bu hastaların evde bakımı akrabalık bağı olan (eş, kızı, oğul, anne, gelin, enişte v.b) 48 
(\%51,61), bakıcı olarak $45(\% 48,38)$ kişi tarafindan sağlandığı bulgusuna ulaşılmıştır (Tablo 5). Hastanede hasta refakatçisi olarak bulunup evde bakım sürecinde de devam eden kişilerin 78 (\%82,11)'nin aynı kişi, 17 (\%17,89)' sinin ise farklı kişiler olduğu tespit edilmiştir (Tablo 5).

Tablo 5. Hasta yakınlarının palyatif bakım yatış süreci ve evde bakım sürecindeki yakınlık durumları ile eğitim alan refakatçilerin evde bakım sürecindeki devamlılık durumları

\begin{tabular}{|l|l|l|}
\hline Palyatif Bakım Yatış Sürecinde Refakatçi Yakınık Durumu & $\mathbf{n}$ & \% \\
\hline Akraba & 175 & 71.72 \\
\hline Bakıcı & 69 & 28.27 \\
\hline Toplam & 244 & 100 \\
\hline Palyatif Bakım Sonrası Evde Bakım Sürecinde Refakatçi Yakınık Durumu & $\mathbf{n}$ & \% \\
\hline Akraba & 48 & 51.61 \\
\hline Bakıcı & 45 & 48.38 \\
\hline Toplam & 93 & 100 \\
\hline Evde Bakım Refekatçi Devamlıı̆̆ı & $\mathbf{n}$ & $\boldsymbol{\%}$ \\
\hline Aynı Kişi ile & 78 & 82.11 \\
\hline Farklı Kişi ile & 17 & 17.89 \\
\hline Toplam & 95 & 100 \\
\hline
\end{tabular}

Evde bakım sürecinde yakınları vefat eden hasta yakınlarına yas sürecinin yeni olması sebebiyle eğitim temasına ilişkin sorular sorulmamıştır. Hayatta olan 72(27.90) hastaya yönelik bulgularda eğitim alma durumu $66(\% 91,66)$, eğitimin kullanılması ve memnuniyet durumu ise eğitim aldığını ifade eden $60(\% 90,90)$ kişi tarafından değerlendirilmiştir. Palyatif bakım sürecinde eğitim alan 60 $(\% 83,33)$, almadıklarını ifade eden $6(\% 8.33)$, değerlendirmede bulunamayan $6(\% 8.33)$ hasta yakınının olduğu bulgusuna ulaşılmıştır (Tablo 6). Palyatif bakımda eğitim alan $60(\% 83,33)$ hasta yakınının değerlendirdiği eğitimi kullanma ve memnuniyet temalarında, eğitimlerin günlük hayatlarında kullanabildiklerini ifade eden $50(\% 83,33)$, kullanamadıklarını ifade eden $10(\% 16,67)$, memnuniyete ilişkin ifadelerinin sonunda ise 54 (\%90) hasta yakınının memnun 6 (\%10) hasta yakınının ise memnun olmadığı bulgusuna ulaşılmıştır (Tablo 6).

Tablo 6. Hasta refakatçilerinin eğitim alma, evde bakım sürecinde kullanma ve eğitimden memnuniyet durumları

\begin{tabular}{|l|l|l|}
\hline Palyatif Bakım Yatış Sürecinde Hasta Refakatinin Eğitim Alma Durumu & n & \% \\
\hline Evet & 60 & 83.33 \\
\hline Hayır & 6 & 8.33 \\
\hline Bilmiyorum & 6 & 8.33 \\
\hline $\begin{array}{l}\text { Toplam } \\
\text { Palyatif Bakım Sırasında Alınan Eğitimin Evde Bakım Sürecinde Kullanım } \\
\text { Durumu }\end{array}$ & $\mathbf{n}$ & $\mathbf{\%}$ \\
\hline
\end{tabular}




\begin{tabular}{|l|l|l|}
\hline Evet & 50 & 83.33 \\
\hline Hayır & 10 & 16.67 \\
\hline Toplam & 60 & 100 \\
\hline Palyatif Bakım Sürecinde Verilen Eğitimden Refakatçilerin Memnuniyet Durumları & $\mathbf{n}$ & $\%$ \\
\hline Evet & 54 & 90 \\
\hline Hayır & 6 & 10 \\
\hline Toplam & 60 & 100 \\
\hline
\end{tabular}

\section{TARTIŞMA ve SONUÇ}

Palyatif bakım ünitesinde yatmakta olan hasta yakınlarına, hasta ve bakım vericinin yaşam kalitesini yükseltmeye yönelik eğitim verilip verilmediği, verilen palyatif bakım eğitimlerinin hastaların taburculuklarından sonra da kullanılıp kullanılmadığının tespiti, eğitimden kazanılan faydaların memnuniyete etkisi, eğitimi alan kişilerin bakım sürecindeki devamlılık durumlarının tespiti amacı ile yapılan bu araştırmada elde edilen bulgular literatür bilgileri doğrultusunda karşılaştırılarak tartışılmıştır.

Palyatif bakımın temel görevlerinden biri, hasta ve ailenin yaşam kalitesini artırmak amacıyla yapılan eğitim çalışmalarıdır. Refakatçilerin yeterli bilgi ve donanıma sahip olmadan birtakım tedavi ve bakım sorumluluklarını üstlenmelerinin hem fiziksel hem ruhsal sağlıkları açısından riskler taşıdığı ifade edilmektedir (Yetener ve Özgün, 1997). Özellikle terminal dönem hastalara hizmet vermesi palyatif bakımda verilmesi gereken eğitim desteğini zorunlu kılmaktadır. Bu amaçla yapılan uygulamaların devamlılı̆̆g hasta ve bakım verici üzerinde büyük önem taşır.

Çalışmamızda palyatif bakım sürecinde $(\% 82,11)$ eğitim alan kişinin evde bakım sürecinde de aynı kişi tarafından devam ettirildiği bulgusuna ulaşılmıştır. Verilen bakımın sürekliliğinin ölüm zamanı ve hastane yatışı üzerine ilişkin verilerin sınırlı olduğu ancak hastaların klinik tabloları üzerine etkisi bulgulamıştır (Hudson et al., 2019). Yeni tanı konmuş hastalarda palyatif bakım sürecinde yapılan uygulamalara erken başlanmasının bakım vericiler üzerinde deneyim ve psikolojik fayda sağladığı, aynı zamanda hasta çıtıları üzerine birçok olumlu sonuç doğurduğu tespit edilmiştir (El-Jawahri et al., 2017; Dionne- Odom et al., 2015). Hasta öğrenim gereksinimlerinin belirlenmesi amacıyla yapılan bir çalışmada, hastaların eğitim gereksinimlerinin yüksek düzeyde olduğu belirlenirken (Özdelikara, Mehtap ve Polat, 2013), bir başka çalışmada bakım verenlerin hasta bakımı konusunda deneyimli olmadığ 1 halde bakımda kendilerini yeterli hissetmeleri ve eğitim gereksinimi bildirmediklerini belirtmişlerdir (Taşdelen ve Ateş, 2012). Bakım sağlayıcıların bakım verme konusundaki bilgilerinin yetersiz olmasının, evde bakılan kişilerin yaşam sürelerinde kısalmaya neden olabileceği (Subaşı ve Öztek. 2006), ve hasta bakımını yapacak olan bireylerin eğitilmesinin yaşlılara götürülen hizmetlerin kalitesini arttıracağını (Bahar ve Parlar. 2007) gösteren çalışmalar literatürde mevcuttur.

Çalışmamızda hasta yakınlarının \%83,33'nün palyatif bakımda aldıkları eğitimi günlük hayatlarında kullanabildiklerini ifade etmişler. Örnek bir çalışma olarak kanser hastasına bakım verenlere uygulanan planlı eğitimlerin bakım verenin algıladığı bakım yükünü azalttığı saptanmıştır (Uğur ve Fadıloğlu, 2013). Bizim çalışmamızda aldıkları eğitimi günlük hayatlarında kullanabilmeleri bakım yükünü azaltmasını destekler niteliktedir. Psiko-eğitimsel müdahalelerin aile bakıcılarına yardımcı olma konusunda etkili olduğu (Hudson et al., 2015) ancak palyatif bakım hizmetinin yaygın şekilde anlaşılması için verilen bilgilerin düşük okuryazarlık düzeyinde verilmesi gerektiği bildirilmişdir (Zhu ve Enguidanos, 2019). Çalışmamızda hasta yakınlarının alınan eğitimi yüksek oranda kullanabildiklerini ifade etmeleri, palyatif bakımda verilen eğitimlerin bakım verici için gerekli olan ihtiyaca cevap verebildiğini göstermektedir. 
Çalışmamızda hasta yakınlarının \%90'nı aldıkları eğitimden memnun olduklarını ifade etmişlerdir. Hasta yakını memnuniyeti genel anlamda, verilen hizmetin hasta yakınının beklentilerini karşılaması ya da hasta yakınlarının verilen hizmeti algılamalarına dayandığı ifade edilemektedir (Tunca ve Aydın, 2016). Yapılan araştırmalarda memnuniyet düzeyinin, eğitim, hasta bakım süresi, yardım ve ölüm zamanı ile anlamlı düzeyde ilişkili olduğu (D'Angelo et al., 2017) bakım verme programlarının aile bakıcıları üzerinde olumlu etkiye sahip olduğunu ve erken dönemde alınan palyatif bakım hizmetlerinin bakım verenlerde memnuniyeti artırdığı bulgusuna ulaşmıştır (Leow, Chan ve Chan, 2015; Mcdonald et al., 2017). Bu durum çalışmamızdaki hasta yakınlarının, hastalarının palyatif bakım ünitesine yatışları sırasında aldıkları eğitimlerden yüksek memnuniyet oranı sergilediklerini ve bunun hasta bakımı üzerinde olumlu etki yarattığını düşündürtmektedir.

Sonuç olarak çalışmamızda, palyatif bakım ünitesinde hasta yakınlarına verilen eğitimden beklenen yararın, taburculuk sonrası üç ay içerisinde yüksek oranda ölüm gerçekleşmesi nedeniyle yaklaşık $\% 40$ oranında hasta ve yakını üzerinde fayda sağlayabileceği görülmüştür. Palyatif bakım ünitesindeki yatışları sırasında bakım veren ve bu süreçte eğitim alan refakatçinin evde bakım sürecinde de $\% 82,11$ oranında aynı kişi olarak devamlılık sağlaması, bu kişilerin evde bakım sürecinde \%83,33 oranında ögrendiklerini hasta bakımında kullanmaları, \%90 oranında ise aldıkları eğitimden memnun olduklarını ifade etmeleri, palyatif bakım eğitimlerinin palyatif bakım ünitesinde eğitim alıp taburcu olduktan sonrada çoğunluklu olarak aynı kişiler tarafından bakımın devam ettirilmesi ile eğitimin katkısının sürdürülebildiği, beklenen hasta ve yakınlarının yaşam kalitesini artırmaya yönelik yararın karşılığını bulduğu sonucuna varılmıştır.

Ayrıca veri kayıt sisteminde hasta bilgilerinin eksik ya da hatalı girilmesi sonucu $70(\% 27,14)$ hastaya ulaşılamaması; veri giriş hatalarının/eksikliklerinin gerekli durumlarda hasta ile iletişimin sağlanamaması riskini ortaya koyduğu ve hasta kayıt sisteminin işlevselliğinin önemini göstermiş̧tir.

\section{KAYNAKÇA}

Avşar G., Kaşıkcı M. (2009). lkemizde hasta eğitiminin durumu. Atatürk Üniversitesi Hemşirelik Yüksekokulu Dergisi, 12(3), 67-73

Aydoğan F., Uygun K. (2011). Kanser hastalarında palyatif tedaviler. Klinik Gelişim, 24(3), 4-9.

Azıznezhad P., Zabihi A., Hossini, S.J., Bighani A. (2010). Nurses and nurse managers opinions about the patients education barrieres. Babol University Medical Science, 12(1), 60-64.

Bahar A.ve Parlar S. (2007). Yaşlılık ve evde bakım. Fırat Sağglı Hizmetleri Dergisi, 2(4), 32-39.

Bruccoliere, T. (2000). How to make patient teaching stick. RN, 63(2), 34-34.

Connor S.R., Bermedo M.C.S. (2014). Global atlas of palliative care at the end of life. Worldwide Palliative Care Alliance (WPCA): World Health Organization.

D’Angelo, D., Punziano, A. C., Mastroianni, C., Marzi, A., Latina, R., Ghezzi, V., ... \& De Marinis, M. G. (2017). Translation and testing of the italian version of FAMCARE-2: Measuring family caregivers' satisfaction with palliative care. Journal of Family Nursing, 23(2), 252-272.

Dionne-Odom, J. N., Azuero, A., Lyons, K. D., Hull, J. G., Tosteson, T., Li, Z., ... \& Hegel, M. T. (2015). Benefits of early versus delayed palliative care to informal family caregivers of patients with advanced cancer: outcomes from the ENABLE III randomized controlled trial. Journal of Clinical Oncology, 33(13), 1446.

El-Jawahri, A., Greer, J. A., Pirl, W. F., Park, E. R., Jackson, V. A., Back, A. L., ... \& Gallagher, E. R. (2017). Effects of early integrated palliative care on caregivers of patients with lung and gastrointestinal cancer: a randomized clinical trial. The Oncologist, 22(12), 1528-1534.

Gültekin M., Özgül N., Olcayto E. ve Tuncer A. M. (2010). Türkiye'de palyatif bakim hizmetlerinin mevcut durumu. Türk Jinekolojik Onkoloji Dergisi, 13(1), 1-6. 
Hoving C.,Visser A., Mullen P.D., Van D.B. (2010). A History of patient education by health professionals in europe and north america: from authority to shared decision making education. Patient Education and Counseling, 78(3), 275-281.

Hudson, B. F., Best, S., Stone, P., \& Noble, T. B. (2019). Impact of informational and relational continuity for people with palliative care needs: A mixed methods rapid review. BMJ Open, 29; 9 (5).

Hudson P., Trauer T., Kelly B., O'Connor M., Thomas K., Zordan R., Ve Summers M. (2015). Reducing the psychological distress of family caregivers of home based palliative care patients: Longer term effects from a randomised controlled trial. Psiko-Onkoloji, 24(1), 19-24.

Kıvanç M. M. (2017). Türkiye'de palyatif bakım hizmetleri. Sağllk Bilimleri ve Meslekleri Dergisi, 4(2), $132-135$.

Leow M., Chan S., Chan A.F. (2015). A pilot random ized, controlled trial of the effectiveness of a psychoeducational intervention on family caregivers of patients w ith advanced cancer. Oncology Nursing Forum, March, 42(2).

Mcdonald J., Swami N.,Hannon B., Lo C., Papa A., Oza A., Leighl N., KrzyzanowskaM.K., Rodin G., Le L.W., Zimmermann C. (2017). Impact of early palliative care on caregivers of patients with advanced cancer: Cluster randomised trial. Onkoloji Annals, January, 28(1), 163-168.

Mollaoğlu M., Özkan Tuncay F., Kars Fertelli T. (2011). inmeli hasta bakım vericilerinde bakım yükü ve etkileyen faktörler. Dokuz Eylül Üniversitesi Hemşirelik Yüksekokulu Elektronik Dergisi , 4(3), 125-130.

Özdelikara, A., Mehtap, T. A. N., Polat, H. (2013). Hasta öğrenim gereksinimlerinin belirlenmesi. Florence nightingale hemşirelik dergisi, 21(1), 1-8.

Özden M. (2003). Sağlık eğitimi ders kitabı. Ankara: Pozitif Tasarım Yayıncılık.

Palyatif bakım hizmetlerinin uygulama usul ve esasları hakkında yönerge (2018). 23 Mayıs 2019 tarihinde https://khgmsaglikhizmetleridb.saglik.gov.tr/TR,42938/palyatif-bakim-hizmetlerininuygulama-usul-ve-esaslari-hakkinda-yonerge.html adresinden erişildi.

Subaşı, N., Öztek, Z. (2006). Türkiye'de karşılanamayan bir gereksinim: Evde bakım hizmeti. TSK Koruyucu Hekimlik Bülteni, 5(1), 19-31.

Şenyuva E., Taşocak G., (2007). Hemşirelerin hasta eğitimi etkinlikleri ve hasta eğitimi süreci. İstanbul Üniversitesi Florence Nightingale Hemşirelik Yüksekokulu Dergisi, 15(59), 100-106.

Taşdelen P., Ateş M. (2012). Evde bakım gerektiren hastaların bakım gereksinimleri ile bakım verenlerin yükünün değerlendirilmesi. Hemşirelikte Eğitim ve Araştırma Dergisi, (3), 22-29

Türk Dil Kurumu. (2005). Türkçe sözlük. Ankara: TDK Yayınları.

Tunca, F. ve Aydın, N. (2016). Yatan hasta yakınlarının sağlık hizmetlerinden memnuniyeti üzerine bir araştırma. Anadolu Bil Meslek Yüksekokulu Dergisi, (42), 73-90.

Uğur, Ö. ve Fadıloğlu, Z. (2013). Kanser hastasına bakım verenlere uygulanan planlı eğitimin bakım veren yükü üzerine etkisi. Cumhuriyet Hemşirelik Dergisi, 1(2), 33-39.

Yetener M., Özgün Y., (1997). Sağlıkta kadın emeği açısından refakatçilik ve refakatçilerin săğı̆̆ı. III. Kadın Hekimlik ve Kadın Să̆lı̆̆ı Kongre Kitabı. Ankara: TTB.

Yıldırım N., Çiftçi B., Kaşıkçı M. (2017). Hemşirelerin hasta eğitimi verme durumu ve etkileyen faktörlerin belirlenmesi. Atatürk Iletişim Dergisi, 14, 217-231.

Whitehead D. (2004). Health promotion and health education: Advancing the concepts. Journal of Advanced Nursing, 47(3), 311-320.

Zhu, Y., Enguídanos, S. (2019). When patients say they know about palliative care, How much do they really understand? Journal of Pain and Symptom Management, 58(3), 460-464. 